\title{
Child Disciplinary Practices versus Child Rights in Zimbabwe: Viewed through Social Work Lenses
}

\author{
Tapiwa Simango
}

Midlands State University, Zimbabwe

\author{
Itai Mafa \\ Midlands State University, Zimbabwe
}

DOI: https://doi.org/10.18778/1733-8077.18.1.06

\section{Keywords:}

Children's Rights;

Disciplinary Methods, Social Work;

Zimbabwe

\begin{abstract}
Although parents are a vital cog in instilling and maintaining child discipline, very little information exists about the methods they employ. Using a qualitative approach, this paper explored the methods used by parents in Zimbabwe-an African context-to discipline children, elucidating their implications on children's rights. The findings show that parents in Zimbabwe use both violent and non-violent disciplinary methods such as verbal reprimand, beating, and spanking, which, at times, violates children's rights in the process. The use of non-violent means has also depicted a violation of children's rights through deprivation of food, denial of playtime and shelter. Evident from the findings was, again, the existence of multiple-layered contestations on child discipline within the socio-cultural discourse-the most popularized being the debate on corporal punishment versus child rights violations. Through social work lenses, the paper provides a basis to dispel an anachronistic thought, which rationalizes the instrumentalization of punishment to achieve child discipline, underscoring the need for child rights-oriented discipline.
\end{abstract}

Ms. Tapiwa Simango is a clinical social worker, social justice advocate, and social work lecturer at the school of social work, Midlands State University.

email address: tgsimang@gmail.com
Dr. Itai Mafa is a social work lecturer at Midlands State University school of social work. She is passionate about social policing, women empowerment, and social inclusion. 


\section{Introduction and Background}

The United Nations Convention on the Rights of the Child (UNCRC) (1989) mandates member states to ensure child protection through the legislature, sound administration systems, and socio-educational means. As such, the High Court of Zimbabwe declared corporal punishment on children illegal, citing inconsistencies with the Zimbabwean Constitution (Mushohwe 2018). The first declaration of constitutional invalidity of corporal punishment was on the 31st of December 2014 by Justice Muremba in the case of State v. Chokuramba. On the 1st of March 2017, Justice Mangota made a similar declaration, also citing inconsistencies of the practice to the provisions of the Zimbabwean Constitution Amendment Number 20 of 2013. The decision preceded a similar judgment on the 31st of December 2014 and was positively appreciated by child rights defenders, although contentiously perceived by parents and guardians as it constitutes part of the disciplinary methods parents employ. This contention, therefore, created a need to understand the parenting practices used in Zimbabwe during the disciplinary process and their effect on children's rights.

Discipline is meant to instill the "do's and don'ts," as well as the "what to" and "what not to" differences when faced with various circumstances. The word discipline is extracted from the Latin word disciplina, which entails teaching or giving guidance. However, it is frequently regarded as being synonymous with control and punishment. Straus (2004) notes that child discipline is an exercise that aims to achieve positive social conduct through the setting of behavioral limits and self-control. It can, thus, be argued that discipline is a process of imparting knowledge and skills needed to navigate through life's challenges. According to Evans (2006), disci- pline involves activating a conducive atmosphere underpinned by positive relations between the parent and the child. It has also been understood to encompass knowledge, as well as developmental training that mold character, self-control, and orderliness.

At birth, Duschinsky (2012) argues that the human mind has no innate ideas, preconceived goals, or predetermined values. It is the process of socialization through different mediums that fills in this gap primarily through the parenting practices, which are adopted during the disciplinary process to instill the desired outcome (Baumrind, Larzelere, and Cowan 2002). It can then be argued that the socialization process is anchored on socio-cultural norms that discourage deviant behavior such as stealing, talking back to elders, being disrespectful derived from shared values such as integrity, respect, and family cohesion. Thus, the process of discipline tries to introduce and reinforce these values in a child, which might, at times, result in the violation of their rights.

UNICEF (2010) notes that principal to any culture is the process of child-rearing, which involves the schooling of self-control, together with behavior that is acceptable to the society. The family setup is the primary institution for socialization and a critical disciplinary entity that builds character and molds favorable norms within the society (Mugumbate and Chereni 2019). The UNCRC (1989), article 5, records the vital guiding role parents and alternate caregivers play in the nurturing course of children's development. Through a structured apprenticeship-like relationship, children anywhere in the world amass their culture to become socially apt beings (Vygotsky 1978). From basic language skills to grooming and deportment, as well as 
couture, this complex process concretizes a child to become a person befit for society. The rationale behind the use of discipline is, therefore, premised on curbing deviance within socially set boundaries derived from a communal set of norms, values, and beliefs (Sadik 2018). Various tools are engaged around the globe to make this possible, inclusive of verbal instruction, coaching, storytelling, proverbial instruction, as well as spanking, which has invoked intense debates surrounding its legality (Amos 2013).

In the African way of life, children are a shared responsibility of everyone in the community (Amos 2013). This position is grounded within the notions of Ubuntu, which envisions the totality of a human being as based on the other. Hence, the maxim, "I am because you are" (Mugumbate and Chereni 2019:28). It is then imperative to note that children and concepts of childhood are not mere abstracts but phenomenologies constructed and born out of the social interpretations of the indigenous folk. The African child-rearing system makes use of folktales and, at times, violent methods, which violate children's rights, such as beating, in an attempt to inculcate positive discipline in children (Amos 2013). Dawkins (1951) defines folktales as a story that is passed from generation to generation through oral tradition. Emery (2012 as cited in Amos 2013) concurs that a folktale is a traditional account, usually mysterious, passed down verbally as a means of instilling virtues in children.

In Zimbabwe, likewise, folktales (ngano) would be narrated by the elderly people to the younger ones to encourage qualities such as giving and caring for one another. Sone (2018) also notes that elderly people would assume the parental role in their word of advice during the storytime, molding the young ones. Thus, the extended family would also come in to discipline the child. Shumba (2001) contends that traditionally, non-violent methods such as proverbs, riddles, folktales, songs, legends, and myths played a critical role in disciplining children aside from corporal punishment. Proverbs are generalized truths that have been accumulated through the experiences of preceding generations with an educational value derived from the past for young ones to emulate or avoid. According to Shumba (2003), these teachings through proverbs also cultivated a sense of responsibility in young persons. For example, Rina manyanga hariputirwe, translating to mean that there is nothing bad done in secret that can be hidden forever, would then encourage the child not to do bad things and act deceptively, assuming that no one will find out as it would always come to light. Sone (2018), however, argues that while the culture of storytelling has since become extinct within the African culture, sustainably beating is still existent. The contemporary era reflects this typology through a mix of both verbal and non-verbal means of discipline.

It can be argued that within this discourse, possible gross child rights atrocities and violations might occur under the guise of producing a well-behaved and socially acceptable person. Hence, the need for further exploration of parental practices employed during the disciplinary process in this context. Regarding this, UNICEF (2010:vii) notes that,

the protection of children from violence is a fundamental right the international community has solemnly pledged to safeguard for all children, everywhere and at all times. Unfortunately, however, violence remains a harsh reality for millions of children around the world and leaves long-lasting consequences on children's lives. 
This is because harsh disciplinary measures, such as corporal punishment, are often used in the African context. Mapara (2009) also notes that from a cultural perspective, beating a child, as well as employing corporal punishment, is generally acceptable. The United Nations General Comment No. 8 (UNCRC 2006) of the UNCRC defines corporal punishment as punishment where physical force is dispensed in anticipation of inflicting a certain level of pain or distress, however light. Straus (2004), in agreement, argues that corporal punishment denotes the deliberate use of physical pain as a means to alter behavior. According to Gershoff (2002), this punishment may constitute slapping, pinching, hitting, kicking, shoving, punching, and choking. Paradoxically, positioning discipline within this context has led to debates on the state of the discipline, corporal punishment, and parental control (Zindi 1995; Shumba 2003; Maphosa and Shumba 2010; Matope and Mugodzwa 2011; Makwanya, Moyo, and Nyenya 2012; Mugabe and Maposa 2013; Gudyanga, Mbengo, and Wadesango 2014; Gambanga 2015; Durrant and Stewart-Tufescu 2017).

According to the Universal Declaration of Human Rights (1948), children's rights are inalienable and should be guaranteed without compromise. The realization of this state of "personhood" is attested by the paradigm shift through the UNCRC (1989), which mandates member states to ensure child protection through the legislature, sound administration systems, and socio-educational means to curb any form of corporal punishment. In Africa, this is affirmed by the African Charter on the Rights and Welfare of Children (ACRWC) Article 1 (OAU 1990), which also ensures that state parties undertake necessary steps consistent with their constitutional processes to enact legislature and other measures necessary for the realization of children's rights.
In Zimbabwe, children's rights formulate part of the national objectives in the Constitution of 2013, under Chapter 2 Section 19. These rights are further detailed under Chapter 4 Part 3 Section 81. The concept of pro-child rights is salient but implicitly stated. For example, Section 811 (e) provides for the protection of children from all forms of abuse. This is buttressed by the general provisions for fundamental human rights and freedoms in Chapter 4 , which ensures the protection of children. These rights include the right to life (Section 48), the right to human dignity (Section 51), the right of freedom from torture or cruel, inhuman, or degrading treatment or punishment (Section 53), and the right to healthcare (Section 76). More so, Chapter 2 Section 19 (1) obligates the state to adopt policies and measures to ensure that children's rights are upheld, realizing the importance of protecting and supporting the family as the basic unit for society (Chapter 2 Section 25). It is within this context that the High Court of Zimbabwe outlawed corporal punishment on children, citing inconsistencies with the Constitution (Mushohwe 2018; Constitution of Zimbabwe Amendment [No. 20] Act 2013). Concerning this, Durrant and Stewart-Tufescu (2017:57) beckons for,

a reframing and restoring of "discipline" as a process of facilitating the development of children's knowledge and understanding, thereby optimizing their development and strengthening their evolving capacities to actualize their rights.

Furthermore, the Children's Act of Zimbabwe (2002), in consistency with the Constitution of Zimbabwe (Constitution of Zimbabwe Amendment [No. 20] Act 2013), provides the practical guidelines to safeguard the welfare and well-being of children in Zimbabwe. The Act obligates social works as the legal guardians for all children. For Ife (2012), social 
work as a human rights-based profession and the vanguard of children's rights is mandated by the law to uphold children's rights (OAU 1990; UNCRC 2006; Children's Act of Zimbabwe [Chapter 5:06] 2002; Constitution of Zimbabwe Amendment [No. 20] Act 2013). This is also validated by the value of social justice, which anchors social work practice. As advocates, social workers are further obligated to protect children from any harmful practice embedded within the disciplinary processes. This, then, positions social workers to ensure that children's rights are upheld at micro, meso, and macro levels of interaction. Given this, the research sought to explore parental practices employed during the disciplinary process and ultimately the impact of these on children's rights.

\section{Problem Statement}

In 2015, Zimbabwe outlawed corporal punishment, a position that was viewed as compromising the role of parents in child discipline. The outlaw was attributed to inconsistencies of corporal punishment with the provisions of the Zimbabwean Constitution Amendment No. 20 of 2013. This decision was judiciously influenced by a few case reviews (Mushohwe 2018), consequently disempowering parents of their disciplinary function. Parents and educators who perpetrate corporal punishment face possible imprisonment under child rights violations or the latter can be suspended from service. However, although the law is clear, there is the persistent use of corporal punishment at different levels in society. This is as a result of the contextual dissonance between the law and indigenous disciplinary practices gravitated by limited knowledge on the subject area. Numerous studies have been done in the country in support of and against corporal punishment (Zindi 1995; Shumba 2003; Chemhuru 2010;
Maphosa and Shumba 2010; Matope and Mugodzwa 2011; Makwanya, Moyo, and Nyenya 2012; Shumba, Ndofirepi, and Musengi 2012; Mugabe and Maposa 2013; Gudyanga, Mbengo, and Wadesango 2014; Gambanga 2015) but fundamentally missing was the parents' narrative and an examination of the varied disciplinary methods they employ (UNICEF 2010). The law adopts a westernized approach to child discipline, which is not harmonized with indigenous parenting practices that uphold the family as the primary disciplinary conduit. This dialectic highly compromises the child protection function, which is a responsibility of multiple stakeholders, including the social work profession in Zimbabwe, because there is a lack of mutual understanding and harmony. As a result, ethical dilemmas emanate in designing evidence-based and culturally-sensitive interventions that enhance child discipline. Social workers handle cases on child delinquency inclusive of drug abuse, truancy, theft, as well as children in conflict with the law. In ensuring sustainable interventions it is, therefore, critical to note the importance of the family as an institution of primary care to ensure positive parenting practices.

\section{Theoretical Frame}

The study was underpinned by Vygotsky's (1978) Social Cultural Theory. The theory postulates that social interaction is principal in the growth of thought and consciousness molding as the individual interacts with the external world. Vygotsky (1978) thus coined the concept of the zone of proximal development (ZPD), where learning refers to apprenticeship guided by capable peers. The theory's relevance in this study is in the exploration of the learning process that concretizes disciplines through three key elements: (1) discipline as a socially-mediated outcome, which results from social 
interactions; (2) children as apprentices or subjects who know nothing but rely on external guidance to master socially acceptable behavior; and lastly, (3) the inter-linkage between child behavior, child discipline, and the society. The theory, therefore, allowed for the exploration of methods employed by parents in disciplining children because it enabled the researchers to understand the interplay of social and cultural influences on what shapes the process of discipline and what defines the standard of what is perceived as a discipline. The theory also allowed researchers to understand the role parents play in the disciplinary process in which they act as guides to children who rely on them to conceptualize what society perceives as acceptable. Lastly, the theoretical framework allowed for an analysis of the methods that parents employed (child discipline) and the greater legal framework of child rights (society) that influences child discipline and child rights violations.

\section{Study Methodology}

The section will cover information on the research participants, the data collection methods, ethical issues, and data analysis.

\section{Methodology}

The study employed a qualitative approach that was descriptive and exploratory in nature, underpinned by the social constructivist paradigm to explore the methods parents in Chimanimani use to instill discipline in their children. A phenomenology design was preferred because it enabled the subject of parental discipline to be studied exhaustively within a natural setting (Neubauer, Witkop, and Varpio 2019). In-depth interviews were used to gather qualitative information from parents of children, as well as from various key informants. Two (2) separate interview schedules were used for the parents and key informants. Chimanimani district was considered appropriate for this study because it has a polarized urban and rural divide in the district, which made it possible to gain insight into both traditional and contemporary disciplinary methods.

\section{Sampling Procedure and Techniques}

Purposive sampling, which is a non-probability technique based on the judgment of the researcher (Engel and Schutt 2009), was used to select the parents and key informants. A selection criterion for parents was developed first to identify study participants with the required characteristics. This was then employed to purposely pick parents who had children under eighteen (18) from the target population in the Chimanimani district. A pastor, a traditional healer, a school principal, and a social worker were selected as key informants based on their expertise and manifold experiences on child discipline, child protection, and children's rights in the targeted district.

\section{Study's Selection Criteria and Sample Size}

The inclusion of study participants was dualistic as it was informed by a selection criterion for the parents and expertise on the part of the key informants. For the parents, the selection criterion was married or single parents with children under the age of eighteen (18) in the Chimanimani district. For interviews, sixteen (16) parents were included based on the principle of saturation. The four (4) key informants were included to give a holistic view of child disciplinary practices. This resulted in a cumulative sample of twenty (20) participants. 
Table 1. Parents' biographical information

\begin{tabular}{|c|c|c|c|c|c|}
\hline Pseudonym & Sex & Age & Level of Education & Marital Status & No. of children \\
\hline A & Female & 35 & Primary & Married & 3 \\
\hline C & Female & 42 & Secondary & Married & 4 \\
\hline E & Female & 27 & Secondary & Single & 2 \\
\hline G & Female & 54 & Secondary & Married & 4 \\
\hline I & Male & 32 & University & Single & 3 \\
\hline J & Male & 38 & Secondary & Married & 4 \\
\hline L & Female & 30 & Technical College & Single & 1 \\
\hline P & Female & 41 & Primary & Married & 4 \\
\hline R & Male & 45 & Primary & Married & 3 \\
\hline S & Male & 49 & Secondary & Married & 5 \\
\hline T & Female & 33 & Secondary & Single & 3 \\
\hline Q & Female & 29 & University & Married & 4 \\
\hline W & Male & 36 & Secondary & Marred & \\
\hline Y & Female & 27 & Secondary & Single & 2 \\
\hline Z & Female & 39 & Technical College & Separated & \\
\hline
\end{tabular}

Source: Self-elaboration.

Table 2. Key informants information

\begin{tabular}{|c|c|c|c|c|c|}
\hline Pseudonym & Sex & Age & Level of education & Occupation & Marital status \\
\hline M & Female & 63 & Primary & Traditional healer & Widowed \\
\hline D & Male & 48 & University & Social worker & Married \\
\hline U & Female & 39 & University & School principal & Single \\
\hline X & Male & 55 & Theological College & Pastor & Married \\
\hline
\end{tabular}

Source: Self-elaboration.

\section{Data Gathering and Analysis}

Data were gathered through a total of twenty (20) interviews that were done over a period of three (3) weeks. The medium of communication was the local language called Chindau, which the researchers were also conversant with. Sixteen (16) interviews were conducted with parents making use of an interview schedule. Also, four (4) key informant interviews were conducted at participants' residential areas and workplaces, according to their preferences, using a different interview schedule with open-end- 
ed questions and probing areas. The interviews lasted between thirty (30) minutes to forty-five minutes (45) due to the nature of the open-ended questions that were asked.

Thematic analysis using steps proposed by Braun and Clarke (2006) was used to analyze data. The researchers familiarized themselves with the data by manually transcribing the recorded interviews. These were read through, making notes on the initial impression, after which initial codes were generated. Open-coding was used as there were no pre-set codes. A review and modification of the themes identified during the initial coding were undertaken to assess their coherence and distinctness. Data relevant for each theme was gathered manually from the transcribed interviews by copying and pasting them to a worksheet (Bree and Gallagher 2016) where themes were defined and analyzed as presented in the findings and discussion.

\section{Ethical Issues}

The study appreciated the sensitivity of the subject under investigation with regards to disclosure of harmful disciplinary practices against children by parents and in observance of the no-harm principle, and deontological-oriented precautionary measures were put in place to protect children if the need arose. This involved the use of social work professional ethics that implore upon the social worker as a researcher to inform relevant authorities if there is a risk of harm or loss of life. To protect the parties involved, informed consent and the voluntary participation of study participants were also observed. Before enrolment, the researchers explained to the prospective study participants the purpose of the study. An effort was made to clarify that participation was voluntary upon which the partici- pants were free to withdraw if at any point they did not feel comfortable proceeding (Engel and Schutt 2009). Confidentiality and anonymity ethics were also employed in safeguarding the identity of the study participants by assigning codes to all participants. There is no legal action that was taken against participants that testified to abusing their children because their confessions were made in retrospect, way after the incidents. To satisfy the ethics of legality, the study got clearance and permission from the District Development Officer, the officer responsible for overseeing any activity conducted in the district. Permission and ethical clearance were also granted by the researchers' institution.

\section{Limitations of the Study}

The study focused on a small sample drawn from the Chimanimani district. This may pose limitations for the transferability of the findings across Zimbabwe. Nonetheless, the triangulation of data sources is believed to have augmented the credibility and dependability of the study findings (Shenton 2004). Furthermore, direct quotes from participants provide insights from study participants as a way of augmenting the trustworthiness of this study and can thus be used to carry out a wider study, which can give a broader understanding of the phenomenon.

\section{Findings and Discussions}

The results generally showed that parents discipline their children with the belief that they will be acting in the best interest of the child. The study further indicated that parents use various dysfunctional methods to discipline children, including beating and spanking, and sometimes burning. These methodologies varied according to parents' prefer- 
ences, their understanding of the discipline, as well as their different temperaments. Parents also employed verbal reprimand and deprivation to achieve child discipline. The study further established the prevalence of discord between the provision of the law and the context. These are explored further in the findings and discussion section below.

\section{Beating and Spanking}

Findings from the study showed that parents beat and spanked their children to achieve desired discipline. This was usually undertaken within the discipline hierarchical system when verbal reprimand was perceived to be ineffective. There were differences in the level of beating, depending on the issue at hand. This was determined by the type of mischief, as well as repetition of a particular offense after a verbal reprimand. Mischief and offenses such as stealing, coming home late, lying, and the use of vulgar language called for a beating. The number of strokes was also determined on count or with the level of remorsefulness of the child. Children from the age of three up to ten were mostly beaten because it was noted that they barely understood concepts when engaged in conversation. This is attested to by the verbatim below:

Personally, I do not like to beat up children and, nowadays, we hear the government no longer allows us to do so, but it is necessary, especially when they continue doing the same thing or when they steal. My husband works away from home, and most of the time, I am left with the children. At times, when you talk to them when they have done mischief, they tend to undermine you. So, at times, I just beat them to gain their respect. I use a belt or a stick, but sometimes, when I am angry, I can use my hands to slap them. I stop beating them when I am satisfied that the pun- ishment has been served or when they apologize during the beating. [Participant A, Interview]

My boy is just five. He is an only child and still too small to understand stuff when you talk to him. He has a tendency of taking you seriously when you change your voice tone or spank him using your hands. I do not beat him because of his age, but I just give a small spanking, only like when he lies or refuses to do something I would have instructed. [Participant $\mathrm{R}$, Interview]

A key informant echoed the importance of explaining the disciplinary process to children before beating them, he noted that,

The Bible says, "spare the rod and spoil the child," and this is what we teach at church. This, however, does not mean parents should just beat up their children for the sake of it. It should be done with love and after it has been explained why the child is being beaten. When a beating is done well, a child should never be left confused about the reasons why they were beaten in the first place. In the country, the beating of children was forbidden because of excessive use of corporal punishment, we know it is also good, but the rod should not be spared too. [Participant X, Key Informant-pastor]

The findings above indicate that parents make use of more than one disciplinary method. This versatility is seen in that they may make use of both non-violent and violent means to discipline children in varied magnitude and hierarchy, with the latter being antagonistic with the provisions of children's rights. The power dynamics argument is also highlighted when mothers use beating to demand respect from their children as the patriarchal leaning in Africa often accords fathers or men disciplinary powers. From the findings, it appears as if this so- 
cial inclination pushes some mothers to adopt harsh disciplinary methodologies to rubber-stamp their authority and the need to be heard, as well. The findings, again, indicate that parents selectively and knowingly make use of spanking and beating to discipline their children, despite knowledge of its illegality in Zimbabwe. It also shows the subjectivity of discipline in that what some parents may perceive as "small beating" is a violation of a child's right. It can, then, be argued that although there is a solid legislative framework, which upholds child rights, physical punishment is still carried out. This is further validated by the Afro Barometer (Ndoma 2017:1), which recorded that $72 \%$ of adults in Zimbabwe supported parents' use of physical means to instill discipline. The church doctrine, as well as socialization traits, seem to justify the use of beating as an acceptable behavior modification route, which is a worrying phenomenon. This violates the right of children to be protected against torture and cruel, inhumane, and degrading treatment or punishment according to Article 19 of the UNCRC (1989), Article 16 of the ACRWC (OAU 1990), and Chapter 4 Section 53 and Section 811 (e) of the Zimbabwean Constitution of 2013 (Constitution of Zimbabwe Amendment [No. 20] Act 2013).

\section{Burning}

The study findings established that parents, at times, use methodologies with lifelong consequences, such as burning, to discipline their children. Burning charcoal and a hot iron are some of the tools parents used to burn children to instill discipline. The findings also revealed that, in these situations, parents concealed the incidences and would not seek medical attention for the children. Parents who sought medical assistance, however, asked their children to lie about the cause of the burns because they were aware of the legal implications. The key informant, a social worker, lamented that children were getting abused through disciplinary measures within their homes and that it was difficult to apprehend the cases since they were hidden or represented falsely. He revealed that children were often threatened or manipulated into silence. They only get to know some of these cases after receiving tips from the victims' neighbors or when the child has been relocated to some other area.

I do not want to speak about this because it makes me feel bad, and I was only young, I did not know how to deal with my first child. Back then, my son stole something from the house, and I noticed it but decided to keep quiet. He then went to play with his friends and came back at the end of the day. In the evening, when I had finished cooking, and he was seated there, too, I took burning charcoal with a spoon and placed it on his hands to punish him. I did not seek medical attention for the child then because I was scared of getting arrested. It is something that I regret a lot, especially now that I am born again. I feel bad every time I see my son, who is now grown up and based in South Africa. [Participant C, Interview]

I suspected my child to have stolen sugar in the house because she had other episodes of doing that. I really never verified, and whilst I had finished ironing, I called her and used the iron to burn her once on those hands that steal. When we went to the hospital, I instructed her to lie to the nurse that the iron had accidentally fallen on her. I did not want any trouble if the truth became known, and I even sent her to my sister's place for a holiday to avoid people asking about it. [Participant N, Interview]

Children can get physically impaired after a heavy beating, and some are traumatized for life. What is 
sad is that the perpetrator will be a trusted parent, and the child usually does not betray this trust relationship by reporting the incident. They can get further threats if they speak out. Some of these cases have come to light through community tip-offs or when death has occurred. [Participant D, Key Informant-social worker]

These disturbing cases are a sad reality of our contemporary society and indicate the unrecorded abuses that children experience in the home environment where they are supposed to be loved and cared for. UNICEF (2010) validates these findings, contending that most violence against children occurs in the home, and very little information about this exists. In this position, children seldom have any power, which leaves them vulnerable and dependent upon the adult, in this case, who is the parent not only for protection but also for guidance. According to this existential state, it can be argued that Vygotsky's (1978) theory is concretized as it reinforces the idea of children being second to adults and acting as apprentices to be socialized about life. The findings further show a parental information and skills gap where some parents end up violating their children's rights because they are unprepared for parenthood. Although there is an existence of a robust legislative framework against corporal punishment, parents still employ this because they are unaware of pro-child rights disciplinary methodologies. Burning a child not only violates the notion of "acting in the best interest of the child" but is also against Article 16 of the ACRWC (OAU 1990) and Article 19 of the UNCRC (1989) on violence and abuse against children. Further, it infringes on the rights of the child to get medical attention according to the Zimbabwean Constitution Chapter 4 Section 76 (Constitution of Zimbabwe Amendment [No. 20] Act 2013), as well as Article 14 of the ACRWC (OAU 1990) and Article 24 of the UNCRC (1989). It can be argued that, in the process of instilling discipline, parents, at times, violate children's rights and underplay their responsibilities as provisioned for by the UNCRC Article 18 (UNCRC 1989) and ACRWC Article 20 (OAU 1990) to ensure that domestic discipline upholds the human dignity of the child.

\section{Verbal Reprimand}

Parents who participated in the study also made use of verbal reprimand, either in its singular form or alongside another disciplinary method when disciplining their children. The findings affirmed that parents' religious affinity influenced their verbatim, which is used when disciplining a child, with some using Bible verses and teachings. This was done to equip and empower children with the life skills needed to navigate between right and wrong behavior. Some parents explained that they would talk, engage, and discuss disciplinary issues with their children. In some instances, scolding, proverbs, and exemplification were also used to get the desired behavior, depending on the gravity of the matter.

We make use of Bible counseling. For the greater part of it, Bible counseling is good and has wisdom. As parents, the Bible gives us the responsibility to do so. Proverbs 13:14 states that those who spare the rod show this, and the Bible says we should train up a child in the way they should grow, and they will not depart from those ways. I feel like the more you talk with your child, they get to understand you better as a parent. This way, mischief can be avoided altogether, because aside from guiding them, you are also giving them the life skills to differentiate between good and bad, and also to be responsible. [Participant E, Interview] 
Personally, I scold my child, sometimes I simply use pfutsek [translating to mean silly], or even at times, when I am really angry, I can compare their behavior to that of a dog. [Participant G, Interview]

In our tradition, we always go back to proverbs, which are wise words with a hidden meaning that is a life lesson. Also, we use similes drawn from real-life experiences within generations. These days, there is rarely the use of folklore because the way of life has changed. It is sad, this generation is lost. I do not know about these things they call rights, a child just says they have them, but they are not old enough to understand. You see, they lack the unhu [humanness] in munhu [person]. Back then, a child was everyone's child, and you would get corrected by anyone on the road. Nowadays, they are too wayward, and we just look at them if they listen, that's it, if they do not, that's it. [Participant M, Key Informant-traditional healer]

The study findings show that there are various forms of verbal reprimand, depending on the parents' choice of approach. More so, the verbatim above testifies to the truism that the use of verbal reprimand does not necessarily mean the absence of child rights violations. Scolding children, and also the use of demeaning or foul language equally constitute child abuse. Contrary to this, the key informant lamented over cultural erosion due to modernity where nuclear families are now the modus operandi for child care. The findings suggest the need to revert to traditional methodologies that could mold holistic behavior where child discipline was every elder's responsibility. There was the unearthing of the existence of rich latent indigenous knowledge derived from African culture, which could be re-adopted as an alternate method of discipline. The extended family and society in its totality would together raise children in society, thereby grounding children in acceptable ways. Such disciplinary methods were applauded for their ability to respect the dignity and rights of the child during a verbal reprimand. This is in line with the values upon which the UNCRC (1989) and the ACRWC (OAU 1990) are founded, with particular bias on Ubuntu, which underpins the ACRWC. The use of proverbs in African Tradition Religion augments Shumba's (2003) argument that proverbs and folklore play a critical role in disciplining children. Findings also affirm Amos' (2013) contention that within the African family setup, there exist alternatives that can help to cultivate positive discipline in children, such as folklore and proverbs. Likewise, Vygotsky's theory postulates that child discipline is a socially mediated outcome that results from social interactions. This is evident in the engagements parents make using verbal reprimand underpinned by indigenous knowledge reflective of this society's culture to yield desired behavior. In line with the notion of indigenization, therefore, there is a need to harmonize social work practice with culturally viable methods whose efficacy has been proven in maintaining and promoting child discipline and children's rights.

\section{Deprivation}

The findings from the study showed that parents made use of deprivation of certain amenities and privileges to impart discipline to their children. The most common type of deprivation noted was that of food and playtime. More so, the deprivation was situational and depended on the mischief thereof. Parents also reported on having employed lockouts as deprivation in instances where their children came home late after the curfew. The duration of the lockout lasted for an hour or overnight. The parent simply denied the child leeway to gain access 
to the house. Parents noted that their children had rights and instead of beating them out of fear of being arrested, would resort to other methods, such as deprivation. Some parents felt that deprivation was more effective compared to other methods.

My child stole some pieces of meat from the stew that was being cooked for supper. I was outside in the garden plucking vegetables. As I was walking back into the kitchen, I caught him in the act. That night, I did not give the boy supper because he had eaten his ahead of dinner. I explained to him that by stealing those pieces of meat, he had already had his supper. He cried and then apologized the following morning. [Participant L, Interview]

My son had not done the homework and went on to play with his friends. When he got back, I simply withdrew playtime and banned him from playing with his friends for a week. The other time he came back home from playing after our agreed curfew, I locked him outside from 19:00 to around 22:30. [Participant W, Interview]

A key informant from a local school noted that,

Children should not just be left to wander around. They need firm guidance, and it is not always that they misbehave that they should be beaten because they get used and get hardened. Parents can even take away favors and minimize things they like to do so that they learn that if you behave badly, you can lose something. However, this should not infringe on the rights of the child. [Participant U, Key Informant-school principal]

The findings above further depict the assumption that non-violent disciplinary methods do not violate the rights of children. It appears from the quotes above that parents avoid physical methods, such as spanking, out of fear of being arrested, not necessarily because of the negative implications such methods have on children. This is reflective of a translation gap where the public has to be educated of the adverse psychosocial effects of violating children's rights, instead of simply threatening parents and guardians with legal actions. Again, evidence from the study suggests that despite the state having put in place measures to curb physical abuse of children at a policy level, its measures have not been undertaken to avail alternate positive disciplinary methods. It is for this reason that parents end up still abusing children with the utility of non-violent methods because the issue of child abuse and rights might not have been properly contextualized. Since the African culture may tolerate some form of disciplinary measures that are a violation of children's rights, these need to be dispelled to ensure child protection to uphold culture relativism. Ife (2012) also argues that cultural relativism is inalienable to the human rights discourse since human existence is meaningless without the culture upon which human survival is anchored on. Therefore, any meaningful interventions that protect children in disciplinary settings should be underpinned by cultural relevance to enhance effectiveness.

\section{Implications and Recommendations for Child Protection}

The conclusions drawn from this paper have various implications on child protection because the term discipline is multi-layered cartilage, influenced by various social indices and thus, affecting the behavioral, emotional, and social facets of a child. This positions the social work profession as the legal guardians of children at the forefront of the discourse of child discipline and child rights 
violations. Firstly, despite the outlawing of corporal punishment, the study established the continued prevalence of child rights violations through violent "disciplinary" measures, such as burning and spanking. According to Article 19 of the UNCRC (1989), children should be protected from all forms of physical and mental violence, even if it means self-inflicted harm. This, therefore, questions the operationalization of child protection laws and policies that are meant to safeguard both the rights and well-being of children.

An implementation gap is also noted and this has adverse implications on the psychological, emotional, and physical development of children. Such a finding reflects on the limitation of the legalistic approach to solving social ills within societies (Mafa, Kang'ethe, and Chikadzi 2020). While it is imperative to have a legal position on the welfare of children, there is a need to look beyond the law and consider methodologies that can ensure the attitudinal change in the way that parents discipline their children. Since the findings also showed that some parents employ these because they are unaware of any alternative disciplinary practices they can adopt, social workers, through their roles as educators and advocators, in partnership with other child-friendly professions, may conduct massive educational and advocacy workshops to teach guardians and parents on child rights, child development, and child discipline. Such a holistic approach is both preventative and educational as it seeks to bring awareness instead of adopting a rather punitive approach.

From the human rights and law in social work standpoint, advocacy should go beyond mere radicalism but should be evidence-based and also framed within the legal context. Thus, social work as the pinnacle of child protection should also be a hallmark of quality research that feeds into national child protection policy frameworks and programming. As such, a recommendation is made that social policing should be grassroots-driven and be native-oriented to curb disharmony between the law and social norms. Fundamentally, the study findings indicate a contextual dissonance between the law and the lived realities of parents. The contestation as perceived by the study participants emanates from child protection policies that do not embody the indigenous culture, which incorporates religion, as well. In this regard, it can be argued that in the context of discipline, culture can be a key determinant in both the methods employed, as well as the interventions instigated to protect children.

A key indicator is the finding that reports the continued beating of children as a method to amass these objet d'art that ultimately shape how they behave despite the provisions of the law. This augments Vygotsky's (1978) proposition that the acquisition of culture to which one belongs is key in psychological development through these artifacts. Objets d'art, which are societal and cultural symbols, are contrived and created by people in the culture, including the simplest of tools, such as cutlery and furniture graduating, to complex psychological objets d'art, such as speech, customs, beliefs, amongst others. Thus, positive cultural reorientation is a necessary intervention to dissuade negative disciplinary practices influenced and backed by culture. The paper, therefore, suggests that social workers, through research, should take due diligence in conducting comprehensive appraisals to establish the alternative disciplinary methods and their efficacy, without which children may continue facing child rights violations in the name of discipline. Such a study may also assist in identifying existent parenting capacity gaps realizing the important role that parents 
play in the disciplinary process to help them adopt positive parenting practices.

Further, the findings revealed that parents may sometimes threaten or manipulate their children into secrecy when their rights are violated. Looking at this from a child protection view, such a finding is worrying and raises questions on the visibility of child protection services. While the study has already highlighted the limitation of the legal approach to handling child protection cases, there are instances where the law has to be invoked and arrange for alternative care for the child until the caregivers are socialized into good parental and disciplinary practices as stipulated in the Children's Act of Zimbabwe (2002). This is with the conviction that every decision made should be done in the best interest of the child. There is, thus, a need for community-based models that are accessible to identify and coordinate such cases for intervention through the case management system within communities and the immediate environment of the child. Such radical programming and advocacy are needed to strengthen and respond to this concealed scourge.

The study established that the absence of physical abuse does not necessarily translate to the absence of child abuse. Efforts should be made, therefore, to explore the extent to which alternate methods to discipline can also be tools for child abuse and child rights violations. From the study, certain children's rights were being violated in the absence of corporal punishment, such as the right to food, shelter, and play, amongst other things (Constitution of Zimbabwe Amendment [No. 20] Act 2013). The research contemplates that the discipline of children is a composite of innumerable factors, which emanate from the micro home environment. Henceforth, this research contends that what is made manifest within the society as a whole is a reflection of what transpires at home. Pursuant to this, social workers should advocate for sustainable policy development that is not only pro-blue print-oriented, but that has a robust monitoring and evaluation framework that holds the state, as well as child protection actors accountable for the funding of the annexure that come with policy or law interpretation, awareness campaigns, and parental capacity development.

It is consequently recommended that there is a need for further research on contemporary debates on child discipline and child abuse towards child rights-based disciplinary practices. It also calls upon the profession through its regulatory bodies to come up with robust coordination, as well as a monitoring and evaluation mechanism to ascertain the extent to which child policies are understood and applied within communities. A recommendation is, therefore, made that child rights activists review programming to focus on holistic mitigation, preparedness, and response measures to deal with child protection issues in Zimbabwe. It can, thus, be argued that the social work profession should advocate for the use of alternate positive disciplinary methods within a guided framework, which is in sync with child protection provisions as enshrined in various statutory instruments.

This will, therefore, lead to programming that empowers both children as rights holders and also builds community resilience to child abuse. Interventions should also be culturally sensitive and embrace the principle of Ubuntu, which strengthens them. For this reason, Mupedziswa (1996) argues for developmental social work that is not only remedial but pro-active. At the center of it all, the protection of children should always be prioritized. In line with 
the tenets of clinical-developmental social work, child discipline should not only be child-focused but thought of rhetorically in long term implications on society at large. Investments should be made at micro, meso, and macro levels to curb disciplinary issues escalating and advancing at the macro level into child delinquency.

\section{Conclusion}

The study has elucidated various methods that parents employ to instill discipline in children. Implications of such methods have also been discussed from both social work and child rights perspectives. It has been established that in the wake of achiev-

\section{References}

Amos, Patricia Mawusi. 2013. "Parenting and CultureEvidence from Some African Communities." Retrieved October 15, 2019 (https://www.intechopen.com/books/ parenting-in-south-american-and-african-contexts/parenting-and-culture-evidence-from-some-african-communities). doi: $10.5772 / 56967$.

Baumrind, Diana, Robert E. Larzelere, and Peter A. Cowan. 2002. “Ordinary Physical Punishment: Is It Harmful? Comment on Gershoff." Psychological Bulletin 128:580-589.

Braun, Virginia and Victoria Clarke. 2006. “Using Thematic Analysis in Psychology." Qualitative Research in Psychology 3:77-101.

Bree, Ronan and Gerry Gallagher. 2016. “Using Microsoft Excel to Code and Thematically Analyze Qualitative Data: A Simple, Cost-Effective Approach." All Ireland Journal of Higher Education 8(2). Retrieved December 04, 2021 (https://docplayer. net/53313318-Using-microsoft-excel-to-code-and-thematically-analyse-qualitative-data-a-simple-cost-effective-approach-ronan-bree.html).

Chemhuru, Munamato. 2010. "Revisiting the Place of Punishment in Zimbabwe's Primary and Secondary School Formal ing child discipline, a myriad of child rights violations occurs in Zimbabwe, although they are rarely documented. The paper has advocated for the need for child protection actors to ensure that parental child discipline is anchored on the humanness of children, their dignity, as well as their rights. Social workers as custodians of children who have been mandated to protect children by the law have been challenged to spearhead the establishment of alternative child rights-oriented disciplinary practices and viable child protection policies in line with cultural diversity. The profession has also been encouraged to reform its service delivery to safeguard the children of Zimbabwe against the infringement of their rights.

Education System." Journal of African Studies and Development 2(7):176-183.

Constitution of Zimbabwe Amendment (No. 20) Act. 2013. Harare: Government Printers.

Dawkins, Richard MacGillivray. 1951. "The Meaning of Folktales." Folklore 62(4):417-429. doi: 10.1080/0015587X.1951.9718070.

Durrant, Joan and Ashley Stewart-Tufescu. 2017. “What Is ‘Discipline' in the Age of Children's Rights?" The International Journal of Children's Rights 25. doi: 10.1163/15718182-02502007.

Duschinsky, Robert. 2012. “'Tabula Rasa' and Human Nature.” Philosophy 87(342):509-529.

Engel, Rafael J. and Russel K. Schutt. 2009. The Practice of Research in Social Work. Los Angeles: Sage.

Evans, Garry W. 2006. "Child Development and the Physical Environment." Annual Review of Psychology 57:423-451.

Gambanga, John. 2015. Is Corporal Punishment Really Bad for Juveniles? Retrieved December 04, 2021 (http://www.zbc.co.zw/ 
news-categories/opinion/51619-is-corporal-punishment-reallybad-for-juveniles).

Gershoff, Elizabeth T. 2002. “Corporal Punishment, Physical Abuse, and the Burden of Proof: Reply to Baumrind, Larzelere, and Cowan (2002), Holden (2002), and Parke (2002)." Psychological Bulletin 128(4):602-611.

Gudyanga, Ephias, Fungai Mbengo, and Newman Wadesango. 2014. "Corporal Punishment in Schools: Issues and Challenges.” Mediterranean Journal of Social Sciences 5(9):493-500.

Ife, Jim. 2012. Human Rights and Social Work: Towards Right-Based Practice. Cape Town: Cambridge University Press.

Mafa, Itai, Simon Kang'ethe, and Victor Chikadzi. 2020. "'Revenge Pornography' and Women Issues: Implications for Social Work Practice and Women's Rights." Journal of Human Rights and Social Work 5(1):118-128. doi: https://doi.org/10.1007/s41134-020-00118-0.

Makwanya, Peter, Wayne Moyo, and Trust Nyenya. 2012. “Perceptions of the Stakeholders towards the Use of Corporal Punishment in Zimbabwean Schools: A Case Study of Bulawayo." International Journal of Asian Social Science 2(8):1231-1239.

Mapara, Jacob. 2009. “Indigenous Knowledge Systems in Zimbabwe: Juxtaposing Postcolonial Theory." The Journal of Pan African Studies 3(1):139-155.

Maphosa, Cosmos and Almon Shumba. 2010. “Educators' Disciplinary Capabilities after the Banning of Corporal Punishment in South African Schools." South African Journal of Education 30(2):387-399.

Matope, Nogget and Tawanda Mugodzwa. 2011. “The Prevalence of Corporal Punishment in Zimbabwean Schools in the Twenty-First Century: A Case Study of Gweru." The Dyke 5(2):95-108.

Mugabe, Jacob Madzviti and Angela Dorcas Maposa. 2013. "Methods of Curbing Learner Misconduct in Zimbabwean Secondary Schools." International Journal on New Trends in Education and Their Implications 4(4):111-122.

Mugumbate, Jacob and Admire Chereni. 2019. "Using African Ubuntu Theory in Social Work with Children in Zimbabwe." African Journal of Social Work 9(1):27-34.

Mupedziswa, Rodrick. 1996. "The Challenges of Economic Development in an African Developing Country: Social Work in Zimbabwe." International Social Work 39(1):41-54. doi: 10.1177/002087289603900104.
Mushohwe, Blessing. 2018. "A Ray of Hope for the Outlawing of Corporal Punishment in Zimbabwe: A Review of Recent Developments." University of Zimbabwe Law Journal 1(1):76-91.

Ndoma, Stephen. 2017. AD165: Majority of Zimbabweans Want Government Out of Private Communications, Religious Speech. Retrieved December 04, 2021 (https://afrobarometer.org/publications/ad165-majority-zimbabweans-want-government-out-private-communications-religious-speech).

Neubauer, Brian E., Catherin T. Witkop, and Lara Varpio. 2019. "How Phenomenology Can Help Us Learn from the Experiences of Others." Perspectives on Medical Education 8(2):90-97. doi: 10.1007/s40037-019-0509-2.

Organization of African Unity [OAU]. 1990. African Charter on the Rights and Welfare of the Child, 11 July 1990. CAB/LEG/24.9/49. Retrieved September 21, 2020 (https://www.refworld.org/docid/3ae6b38c18.html).

Sadik, Fatma. 2018. "Children and Discipline: Investigating Secondary School Students' Perception of Discipline through Metaphors." European Journal of Educational Research 7:31-45. doi: 10.12973/eu-jer.7.1.31.

Shenton, Andrew. 2004. "Strategies for Ensuring Trustworthiness in Qualitative Research Projects." Education for Information 22(2):63-75. doi: https://doi.org/10.3233/EFI-2004-22201.

Shumba, Almon. 2001. "Epidemiology and Etiology of Reported Cases of Child Abuse in Zimbabwean Primary Schools." Child Abuse and Neglect 25:265-277.

Shumba, Almon. 2003. “Children's Rights in Schools: What Do Teachers Know?" Child Abuse 12:251-260.

Shumba, Almon, Amasa Philip Ndofirepi, and Martin Musengi. 2012. "An Exploratory Study of Corporal Punishment by Teachers in Zimbabwean Schools: Issues and Challenges." International Journal of Educational Science 4(3):279-287.

Sone, Enongene Mirabeau. 2018. "The Folktale and Social Values in Traditional Africa." Eastern African Literary and Cultural Studies 4(2):142-159. doi: 10.1080/23277408.2018.1485314.

Straus, Martha. 2004. “Corporal Punishment and Primary Prevention of Physical Abuse." Child Abuse and Neglect 24(9)11091114.

The Universal Declaration of Human Rights. 1948. New York: United Nations Department of Public Information. 
The Children's Act of Zimbabwe (Chapter 5:06). 2002. Harare: Government Printers.

UN Committee on the Rights of the Child [UNCRC] General Comment No. 8. 2006. The Right of the Child to Protection from Corporal Punishment and Other Cruel or Degrading Forms of Punishment (Arts. 19; 28, Para. 2; and 37, inter alia). CRC/C/GC/8. Retrieved September 21, 2020 (https://www.refworld.org/docid/460bc7772.html).

UN Convention on the Rights of the Child. [UNCRC]. 1989. United Nations, Treaty Series, vol. 1577, p. 3. UN General Assembly. Retrieved September 21, 2020 (https://www.refworld. org/docid/3ae6b38f0.html).
UNICEF. 2010. Child Disciplinary Practices at Home: Evidence from a Range of Low- and Middle-Income Countries. New York: UNICEF. Retrieved December 04, 2021 (https://data.unicef.org/resources/ child-disciplinary-practices-at-home-evidence-from-a-rangeof-low-and-middle-income-countries/).

Vygotsky, Lev Semyonovich. 1978. Mind in Society: The Development of Higher Psychological Processes. Cambridge, MA: Harvard University Press.

Zindi, Fred. 1995. "An Analysis of Arguments for and against Corporal Punishment in Zimbabwe." Zimbabwe Journal of Educational Research 7(7):69-83.

\section{Citation}

Simango, Tapiwa and Itai Mafa. 2022. "Child Disciplinary Practices versus Child Rights in Zimbabwe: Viewed through Social Work Lenses." Qualitative Sociology Review 18(1):114-131. Retrieved Month, Year (http://www.qualitativesociologyreview.org/ ENG/archive_eng.php). DOI: https://doi.org/10.18778/1733-8077.18.1.06 